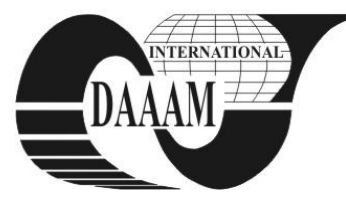

Annals of DAAAM for 2011 \& Proceedings of the 22nd International DAAAM Symposium, Volume 22, No. 1, ISSN 1726-9679 ISBN 978-3-901509-83-4, Editor B. Katalinic, Published by DAAAM International, Vienna, Austria, EU, 2011 Make Harmony between Technology and Nature, and Your Mind will Fly Free as a Bird

\title{
MICROHARDNESS OF MODIFIED THERMOPLASTICS
}

\author{
OVSIK, M[artin]; MANAS, D[avid]; STANEK, M[ichal]; MANAS, M[iroslav]; CERNY, J[akub]; \\ BEDNARIK, M[artin] \& MIZERA, A[les]
}

\begin{abstract}
The submitted article presents the assessment of mechanical properties (microhardness) of the surface layer of modified polypropylene. Hard surface layer was made using the technology of radiation cross-linking, which enables modification of polymer materials and hence the change of their end-use properties. The process of mechanical stress is applied by microhardness test. The surface layer of polymer material such as polypropylene is modified by $\beta$ - radiation. After the polypropylene is subjected to radiation, changes of the surface layer at applied load are observed. Material properties of the created surface layer are measured by microhardness test.
\end{abstract}

Key words: polypropylene, microhardness, irradiation, crosslinking

\section{INTRODUCTION}

The cross-linking of rubbers and thermoplastic polymers is a well-proven process of the improvement of the thermal properties.

The chemical cross-linking or rubber vulcanization is normally induced by the effect of heating after processing with the presence of a curing agent (Krumal et al., 2010).

The cross-linking process for thermosets is very similar. In thermosets the polymer molecules are also chemically linked due to heat after processing .

Cross-linked rubbers have a wide-meshed molecular network that keeps them soft and their properties change only slightly on a wide temperature scale. On the other hand, thermosets are characterized by a very narrow-meshed network. Due to this fact they hardly change their high level of stiffness on a wide temperature scale (Kyas et al., 2010).

The irradiation cross-linking of thermoplastic materials via electron beam or cobalt 60 (gamma rays) is proceeding separately after the processing. The cross-linking level can be adjusted by the irradiation dosage and often by means of a cross-linking booster .

The main deference between beta and gamma rays lies in their different abilities of penetrating the irradiated material. Gamma rays have a high penetration capacity. The penetration capacity of electron rays depends on the energy of the accelerated electrons.

Due to electron accelerators, the required dose can be applied within seconds, whereas several hours are required in the gamma radiation plant (Manas et al., 2009).

The principle of irradiation using Gamma and Electron rays and the ability of penetrating the irradiated material are given in the Fig. 1.

Cobalt 60 serves as the source of radiation in the gamma radiation plant. Many of these radiation sources are arranged in a frame in such a way that the radiation field is as uniform as possible. The palleted products are conveyed through the radiation field. The radiation dose is applied gradually, that is to say, in several stages, whereby the palleted products are conveyed around the Co -60 radiation sources several times. This process also permits the application of different radiation doses from one product type to another. It can be used for irradiation of polyolefines, polyesters, halogen polymer and polyamids from thermoplastics group, elastomers and thermoplastic elastomers. Some of them need the addition of crosslinking agent.

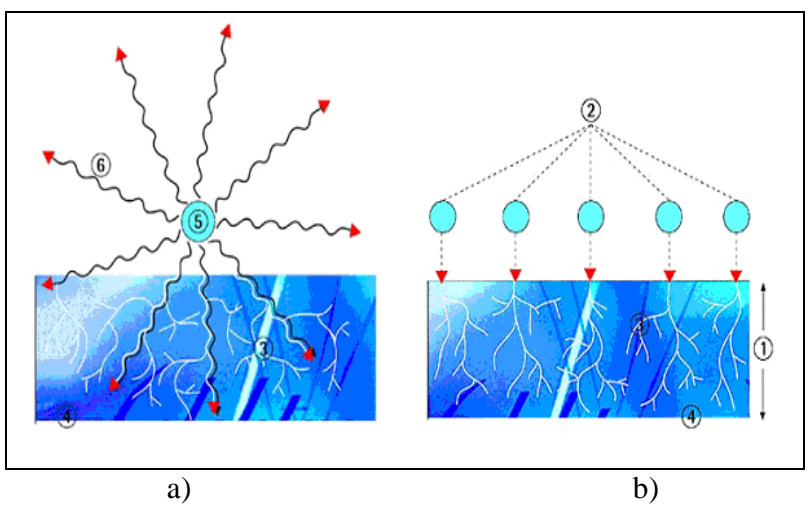

Fig. 1. Design of Gamma rays (a) and Electron rays (b) a) 3 - secondary electrons, 4 - irradiated material, 5 encapsulated $\mathrm{Co}-60$ radiation source, 6 - Gamma rays

b) 1 - penetration depth of electron, 2 - primary electron, 3 secondary electron, 4 - irradiated material

The dimensional stability, strength, chemical resistance and wear of polymers can be improved by irradiation. Irradiation cross-linking normally creates higher strength as well as reduced creep under load if the application temperature is above the glass transition temperature ( $\mathrm{Tg}$ ) and below the former melting point.

Tested polymer:

- $\quad$ PTS - Crealen EP - 2300L1 - M800 (unfilled PP)

Irradiation was realized in the work of the firm BGS Beta Gamma Service GmbH \& Co, KG, Saal am Donau, Germany with the electron rays, electron energy $10 \mathrm{MeV}$, doses minimum of $0,30,45,60,90 \mathrm{kGy}$.

\subsection{Micro-hardness according to Vickers}

Test of hardness according to Vickers is prescribed by European standard ČSN EN ISO 6507-1.

The penetrating body - made of diamond shaped as a regular tetragonal pyramid with the square base and with preset vertex angle $\left(136^{\circ}\right)$ between opposite walls - is pushed against the surface of testing body. Then, the diagonal size of the dint left after load removal is measured (Fig. 2) (Oliver et al., 1992).

Vickers' microhardness is then expressed as the ratio of the testing load applied to dint area in form of regular tetragonal pyramid with square base and the vertex angle equal to the angle of penetrating body $\left(136^{\circ}\right)$. 


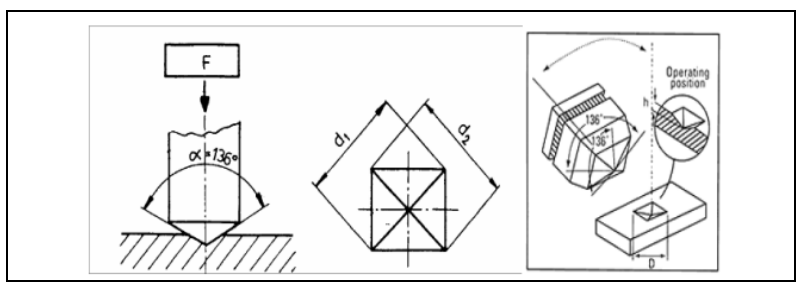

Fig. 2. The basic principle of hardness testing according to Vickers

$$
F=0,1891 \times\left(F / d^{2}\right)
$$

Where:

$\mathrm{F}$ - Testing load in $\mathrm{N}$

$\mathrm{d}$ - Arithmetic average of two diagonals $\mathrm{d} 1, \mathrm{~d} 2 \mathrm{in} \mathrm{mm}$.

\subsection{Micro-hardness testing according to Vickers}

A device used for micro-hardness testing is called microhardness tester [Manas et al 2011].

\begin{tabular}{|c|c|}
\hline \multirow{2}{*}{ Load } & $200 \mathrm{~g}$ \\
& $(\mathrm{HV} 0,2 \quad \mathrm{~F}=1,961 \mathrm{~N})$ \\
\hline Load time & $90 \mathrm{~s}$ \\
\hline
\end{tabular}

Tab. 1. Measurement conditions

The measurement is done by means of digital microhardness tester DM 2D from AFFRI. Measurement conditions are stated in the Tab. The tester is able to measure the hardness according to Vickers as well as according to Knoop. An inbuilt 16bit monolithic high-power microprocessor equipped by photomechanical software was used. Its power can be fully adjusted according to the needs of micro-hardness testing in new century (Oliver et al., 2004).

\section{RESULTS AND DISCUSSION}

For the experimental part the selected polymer material was polypropylene (PP). The PP material was used unfilled. The radiation doses used for PP (unfilled) were 30, 45, 60 and $90 \mathrm{kGy}$. The selected polymer material is industrially produced and processed. The values measured for microhardness were put into graph and evaluated. Ten measurements of microhardness were conducted on each specimen. The selected types of material were monitored for changes of mechanical properties (microhardness) of the surface layer, or their material parameters.

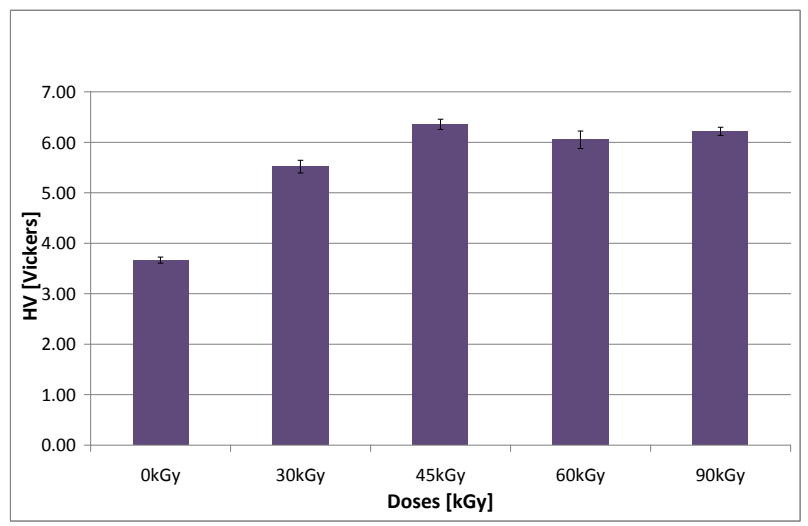

Fig. 3. Microhardness (Vickers)

The values measured during microhardness test showed that the lowest values of microhardness (Vickers) were found for the non-irradiated PP. On the contrary, the highest values of microhardness were obtained for PP irradiated by dose of 45 kGy (by 75\% higher in comparison with the non-irradiated PP), as can be seen at Fig. 3 and Fig. 4. Higher radiation dose does not influence the microhardness value significantly. Increase in microhardness in the surface layer is caused by cross-linking resulting from the radiation of the tested specimen. Upon closer look at the results of microhardness, it is obvious that when the highest radiation doses are used, microhardness decreases which can be caused by material degradation caused by radiation.

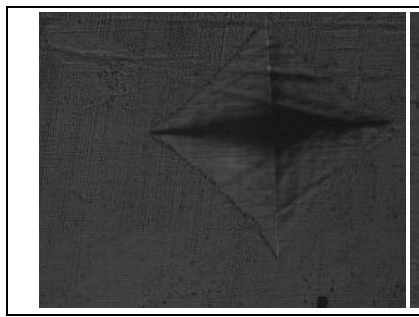

a)

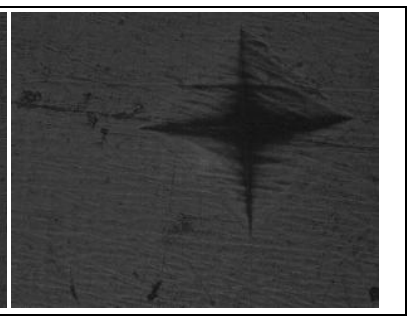

Fig. 4. Vickers indentation produced on PP a) $0 \mathrm{kGy}$, b) 60kGy

\section{CONCLUSION}

The submitted article deals with the problem of measurement of microhardness of modified surface layers of technical materials. Polypropylene (PP) material was selected for the experimental part. The PP material was modified by radiation with beta radiation doses of $30,45,60$ and $90 \mathrm{kGy}$. The values measured were put into graph and evaluated.

Very interesting results were found for PP modified by radiation. When comparing the irradiated and non-irradiated PP it was apparent that the values of microhardness (Vickers) and the considerably increased, in some cases even by $75 \%$ at the irradiation dose of $45 \mathrm{kGy}$.

\section{ACKNOWLEDGEMENTS}

This article is supported by the internal grant of TBU in Zlín No. IGA/10/FT/11/D funded from the resources of specific university research.

\section{REFERENCES}

Krumal, M.; Stanek, M.; Manas, M.; Manas, D.; Kyas, K. \& Cerny, J. (2010). Fluidity of Thermoplastic Elastomers, $D A A A M$, p. 1185 , ISSN 1726-9679, ISBN 978-3-90150973-5, Zadar, Croatia

Kyas K.; Stanek M.; Manas M.; Manas D.; Krumal M. \& Cerny J. (2010). DAAAM, p. 1081, ISSN 1726-9679, ISBN 978-3901509-73-5, Zadar, Croatia

Manas, D.; Manas, M.; Stanek, M.; Sanda, S. \& Pata, V.(2011) Thermal effects on steel at different methods separation, Chemicke Listy 105 (17), ISSN 0009-2770, pp. s713-s3716

Manas, D.; Stanek, M.; Manas, M.; Pata V. \& Javorik, J. (2009). Influence of Mechanical Properties on Wear of Heavily Stressed Rubber Parts, KGK - Kautschuk Gummi Kunststoffe, 62. Jahrgang, , ISSN 0948-3276, p.240-245

Oliver W.C.; G.M. Pharr. (2004). Measurement of hardness and elastic modulus by instrumented indentation: Advances in understanding and refinements to methodology. Journal of Materials Research. vol. 19, no. 1, p. $3-20$

Oliver W.C.; G.M. Pharr. (1992) An improved technique for determining hardness and elastic modulus using load and displacement sensing indentation, J Mater Res 7 (6) pp. $1564-1583$ 